\title{
Homogeneous catalytic formic acid dehydrogenation in aqueous solution using ruthenium arene phosphine catalysts
}

\author{
Cornel Fink*, Lu Chen, and Gábor Laurenczy*
}

Dedication

This paper is dedicated to Prof. Dr. Peter Comba on the occasion of his $65^{\text {th }}$ birthday.

\begin{abstract}
In this work, we studied catalytic formic acid dehydrogenation with a homogeneous RAPTA type precatalyst in aqueous solution. The effects of an amino group, attached to the arene, and the impact of a second equivalent of 1,3,5-triaza-7phosphaadamantane (PTA) added in-situ to the reaction were evaluated. The initial compound, [ $\eta^{6}$ benzyldimethylamine) $\mathrm{Ru}(\mathrm{PTA}) \mathrm{Cl}_{2}$ ] (3), was synthesized and proved to be moderately active for selective formic acid dehydrogenation. The addition of a second equivalent of PTA at the beginning of the reaction significantly improved the catalytic performance. The activation energies for both catalytic systems were assessed via an Arrhenius plot. ${ }^{1} \mathrm{H}$-and ${ }^{13} \mathrm{C}-\mathrm{NMR}$ spectroscopy was used to follow the course of the reaction online and verified complete consumption of substrate. A triplet signal was observed in the hydride region along with its corresponding coupling counterpart in ${ }^{31} \mathrm{P}$ spectra.
\end{abstract}

\section{Introduction}

In 2017, "The Guardian" released an article entitled "Want to fight climate change? Have fewer children", stating that "...by far the biggest ultimate impact is having one fewer child, which the researchers calculated equated to a reduction of 58.6 tonnes of $\mathrm{CO}_{2}$ for each year of a parent's life.". ${ }^{[1]}$ As a matter of facts, the world population is continuously growing, and rising living standards become apparent in many societies. Both factors contribute to an ever-increasing demand for energy. Currently, the primary energy sources are fossils fuels, namely coal, gas, and petrol, which release carbon dioxide $\left(\mathrm{CO}_{2}\right)$ upon their combustion with oxygen. In the earth atmosphere, carbon dioxide acts as a greenhouse gas, contributing to phenomena known as global warming and in further extend, climate change. ${ }^{[2]} \mathrm{A}$ possible solution to break this vicious cycle could be to switch to renewable energy sources by harvesting energy from natural occurrences such as wind or sun. One significant disadvantage of solar and aeolian driven energy generation is their fluctuating nature and in most cases incompatibility with a mobile application. A system needs to be put in place to compensate for the gaps in primary production. The electrolysis of water to hydrogen and oxygen allows a simple transition from electrical to chemical

Institut des Sciences et Ingénierie Chimiques

École Polytechnique Fédérale de Lausanne (EPFL)

$\mathrm{CH}-1015$ Lausanne (Switzerland)

Fax : (+41)21-693-9780

E-mail: cornel.fink@epfl.ch, gabor.laurenczy@epfl.ch energy, in which hydrogen becomes an energy carrier. ${ }^{[3]}$ Fuel cell technology converts hydrogen efficiently on demand back to electrical energy. As of now, no fully satisfying hydrogen storage technology for large-scale application has been developed. Compression and liquefaction of gaseous hydrogen require significant amounts of energy and in both methods are inherently unsafe processes since they involve the handling of highly pressurized containers or liquefied hydrogen. ${ }^{[4]}$

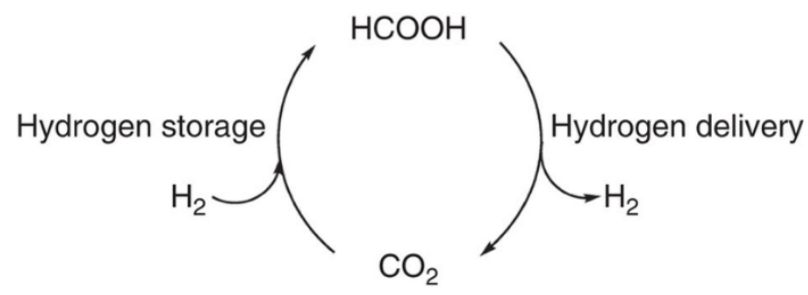

Figure 1 The formic acid/carbon dioxide cycle for reversible hydrogen storage ${ }^{[5]}$

Chemical storage of hydrogen in the form of liquid organic hydrogen carriers (LOHC $)^{[6]}$ is an attractive solution, offering a range of advantages. Formic acid unites some wanted properties such as a high hydrogen content of $53 \mathrm{~g} / \mathrm{L}$, equal to a 700 bar pressurized cylinder, inflammable $(85 \%$ in water), no bioaccumulation, posing, therefore, no environmental risk and is easy to handle since it is a liquid at ambient temperature. ${ }^{[7]}$ The production of formic acid in a sustainable way can be accomplished by $\mathrm{CO}_{2}$ hydrogenation in the presence of appropriate catalysts. Hydrogen delivery from formic acid requires as well a catalyst, providing then hydrogen with an overall storage efficiency of $100 \%$. Both reactions are the two halves of the formic acid/carbon dioxide cycle for reversible hydrogen storage (Figure 1 ), which is a schematic representation of a hydrogen battery. ${ }^{[8]}$

Both, the homogeneous catalytic formic acid dehydrogenation and the carbon dioxide hydrogenation can take place in different solvents, including water, organic solvents, and ionic liquids. ${ }^{[9]}$ The effect, the solvents exert on chemical reactions is profound, and additives are used to shift reaction equilibria. ${ }^{[10]}$ Suitable transfer hydrogen catalysts comprise numerous platinum group metal complexes with $\mathrm{Ru}^{[11]}$ and $\mathrm{Ir}^{[12]}$ as a central ion. Often the ligands contain phosphorus ${ }^{[5]}$, nitrogen donor atoms ${ }^{[13]}, \eta^{6}$ aromatic structures ${ }^{[14]}$ or being pincer-type complexes. ${ }^{[15]}$ Recently, Himeda and coworkers reported on a Cp*Ir catalyst with an $\mathrm{N}$-phenylpicolinamide ligand, reaching a TOF of $118000 \mathrm{~h}^{-1}$ at $60^{\circ} \mathrm{C}$ and a constant dehydrogenation rate of $35000 \mathrm{~h}^{-1}$ over six hours at $50{ }^{\circ} \mathrm{C}$ (TON 1000000$) \cdot{ }^{[16]}$ However, for industrial application, first-row transition metal catalysts are desirable and this for many reasons, but mainly because they are cheap and abundant. Especially for iron catalysts, the recent developments 
in the field are remarkable. ${ }^{[17]}$ There are recommendable review papers available. ${ }^{[17]}$ Heterogeneous catalysts, heterogenized complexes, nanoparticles, nanostructures have also been proven to be active in the hydrogen storage/delivery in the formic acid/carbon dioxide couple, as reviewed by Himeda et al. ${ }^{[18]}$

Ruthenium-arene complexes equipped with 1,3,5-triaza-7phosphatricyclo-[3.3.1.1]decane ligand (PTA), commonly known as RAPTA, became famous for their cytostatic properties. ${ }^{[19]}$ Particularly well known are RAPTA-C ${ }^{[20]}$ (cymene) and RAPTA-

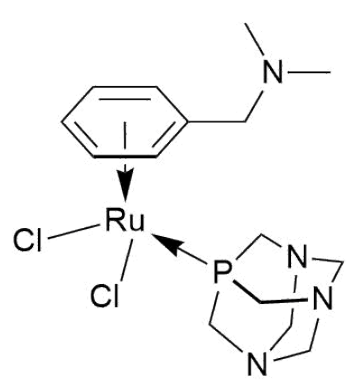

Figure 2 RAPTA type precatalyst (3)
$T$. ${ }^{21]}$ The compound depicted in

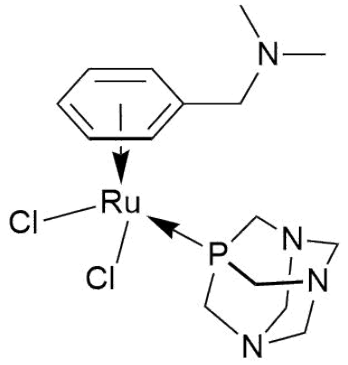

Figure 2 was initially studied by Dyson et al. in 2006 upon its cytotoxicity. ${ }^{[22]}$ Besides their cytostatic properties, it was discovered that $\eta^{6}$-areneruthenium(II) complexes, among them RAPTA ${ }^{[23]}$ and related structures, ${ }^{[24]}$ own catalytic properties for several types of reactions, including transfer hydrogenation. ${ }^{[25]}$

Here, we investigated a catalytic system for formic acid dehydrogenation in aqueous media with $\left[\left(\eta^{6}-\right.\right.$ benzyldimethylamine) $\mathrm{Ru}(\mathrm{PTA}) \mathrm{Cl}_{2}$ ] (3) as a precatalyst, which is synthesized from dimeric $\left[\left(\eta^{6} \text {-benzyldimethylamine }\right) \mathrm{RuCl}_{2}\right]_{2}$ (2) and one equivalent of PTA per Ru-center. The dimethylated amino group connects via a single $\mathrm{CH}_{2}$ linker to the arene. The amino group introduces a range of new possibilities and features to the molecule compared to purely aliphatic aromatics. In the first place, the solubility in aqueous media is considerably increased but also from a mechanistic point of view, the in acidic media positively charged trialkylammonium functionality, offers interesting options. An important aspect when selecting this arene was that the amino group could help to coordinate substrate molecules via hydrogen bonding and also stabilize intermediates during the dehydrogenation process through its charge via an outer-sphere mechanism. ${ }^{[12 \mathrm{~b}, 26]}$ It should be mentioned that the linker measures only one carbon atom to prevent the amino moiety from interacting directly with the ruthenium center via its lone pair. ${ }^{[21 a]}$ The PTA, on the other hand, provides steric protection by its bulky cage-like structure, and the phosphine donates electron density towards the center to render it less prone to reduction by formic acid or dihydrogen. Also, PTA increases the solubility in aqueous media, especially in a protonated state in an acidic milieu.

\section{Results and Discussion}

Compound $\mathbf{3}$ was synthesized, characterized via NMR -and mass spectroscopy and subsequently studied to explore the potential towards formic acid dehydrogenation. The catalytic activity was assessed by dehydrogenating a defined amount of formic acid and following the process with two orthogonal techniques. During dehydrogenation, formic acid releases hydrogen and carbon dioxide in equal amounts, causing a pressure increase in a closed tube, which can, when recorded over time, be correlated with the reaction progress. The complex which is added to the watersubstrate mixture is considered as a precatalyst and undergoes ligand exchange of labile chloride ligands to become the catalytically active species, as was described by Guan et al. for the similar complex [(p-cymene $) \mathrm{Ru}\left(2,2^{\prime}\right.$-biimidazoline $\left.) \mathrm{Cl}\right] \mathrm{Cl} .{ }^{[14 \mathrm{~b}]} \mathrm{At}$ the end of the reaction, pressure increase levels off and finally stops (Figure 3).

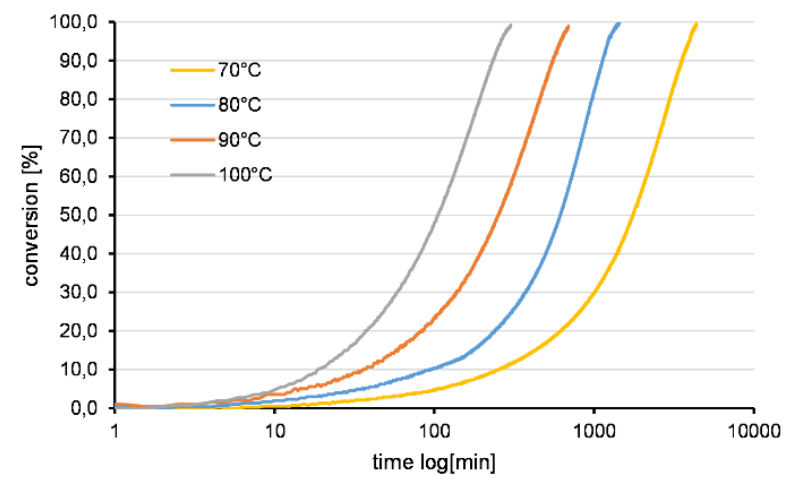

Figure 3 Conversion of FA (dehydrogenation) vs. time [ $\left(\eta^{6}\right.$-benzyldimethylamine) $\mathrm{Ru}(\mathrm{PTA}) \mathrm{Cl}_{2}$ ] to $\mathrm{CO}_{2}$ and $\mathrm{H}_{2}$ at $70-100^{\circ} \mathrm{C}$; $222 \mathrm{mg}$ FA in $1778 \mathrm{mg}$ water and catalyst load $0.0165 \mathrm{M}$

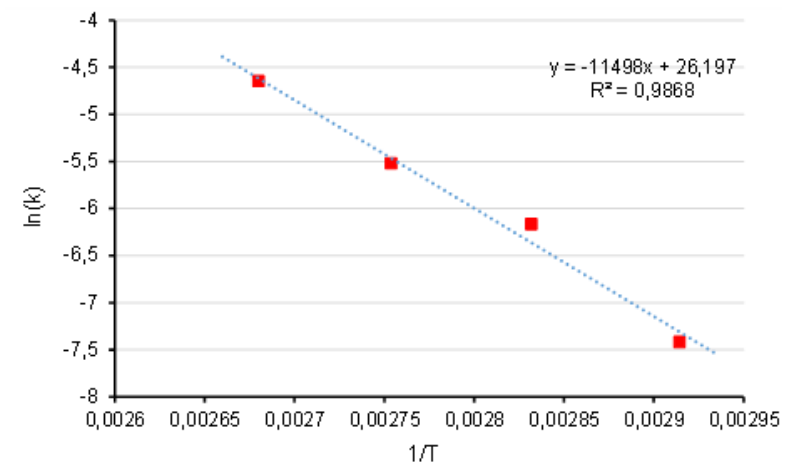

Figure 4 Arrhenius plot to determine the $E_{a}$ of the catalyst (3); the necessary kinetic data was derived from pressure vs. time curves, only the linear part of the curves was taken into consideration for the extraction of kinetic data

The activation parameters were processed via an Arrhenius plot, and the activation energy $\left(E_{a}\right)$ was determined to be $95.59 \pm 4$ $\mathrm{kJ} / \mathrm{mol}$. The found $E_{a}$ is higher than other in literature reported values for the same reaction with iridium $(77.94 \pm 3.2 \mathrm{~kJ} / \mathrm{mol}$, $\left[\mathrm{Cp}^{*} \operatorname{Ir}(1,2\right.$-diaminocyclohexane $\left.\left.) \mathrm{Cl}\right] \mathrm{Cl}\right)^{[12 \mathrm{c}]}$ or iron $(+76.05 \pm 7$ $\mathrm{kJ} / \mathrm{mol}$, [Fe( $\left.\left.\mathrm{PP}_{3} \mathrm{TS}\right)\right]$, where $\mathrm{PP}_{3} \mathrm{TS}$ is m-trisulfonated-tris[2(diphenylphosphino)ethyl]phosphine sodium salt). ${ }^{[2]}$ The catalyst dehydrogenated the formic acid entirely, but when attempting recycling experiments, the catalyst showed signs of degradation and the catalytic activity broke in. From the formation of black debris and metallic depositions on the walls of the tube was deduced that reduction of the Rull center is the most plausible cause for inactivation and further reasoned that a second PTA could provide improved compound stability.

In 2004, Kathó et al. reported on a water-soluble $\left(\eta^{6}-\right.$ arene)ruthenium(II)-phosphine complexes (arenes are benzene and p-cymene) and their catalytic activity in bicarbonate hydrogenation in aqueous solution. ${ }^{[28]}$ Of particular interest to us was the described mode of catalyst formation, which was accomplished by in-situ combination of the dinuclear metal 
precursor and the desired amount of PTA in the reaction vessel. Among other mutually catalytically active species, they suggest $\left[\left(\eta^{6} \text {-arene }\right) \mathrm{Ru}(\mathrm{PTA})_{2} \mathrm{H}\right]^{+}$as intermediate structure. A structurally related compound, $\left[\left(\eta^{6}-p\right.\right.$-cymene $\left.) \mathrm{Ru}(\mathrm{PTA})_{2} \mathrm{Cl}\right] \mathrm{BPh}_{4}$, was described by Peruzzini et al. in 2008. ${ }^{[29]}$ Accordingly, we combined the precatalyst 3 in water with one equivalent PTA, added substrate and started the reaction. First, we observed a color change from shades of red to an orange-yellow solution, then an increased catalytic activity (Figure 5).

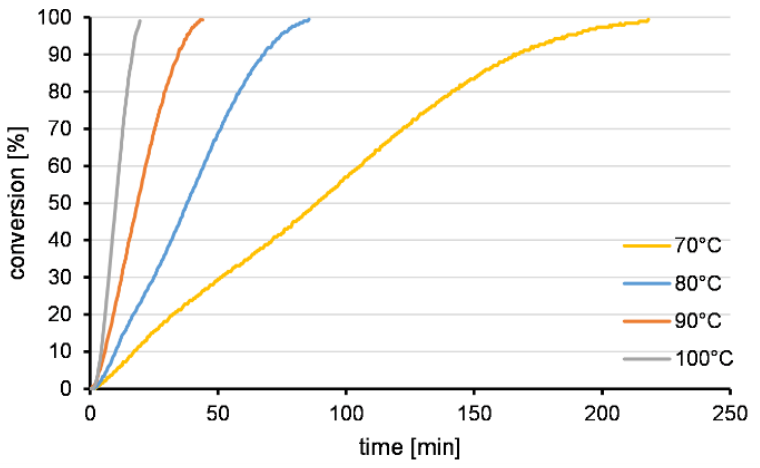

Figure 5 Conversion of FA (dehydrogenation) vs. time at different temperatures $\left(70-100^{\circ} \mathrm{C}\right)$; catalyst: in-situ generated catalyst;

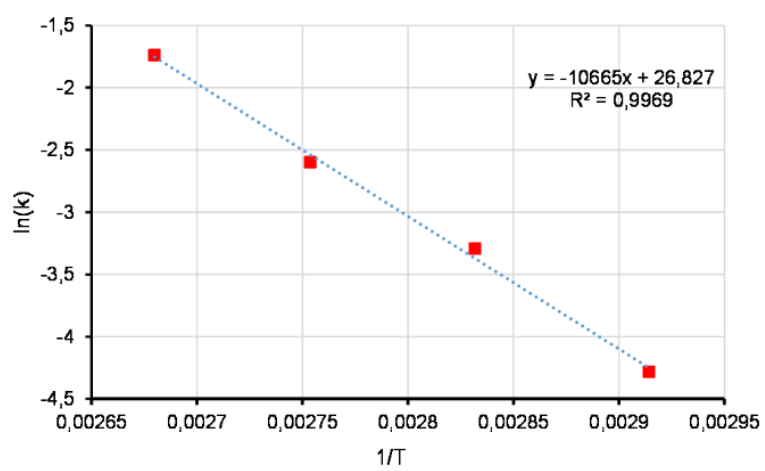

Figure 6 Arrhenius plot to determine the $E_{a}$ of the in-situ formed species; the necessary kinetic data was derived from pressure measurements (Figure 5);

The activation energy was assessed via an Arrhenius plot (Figure $6)$ and the apparent activation energy $\left(E_{a}\right)$ was determined to be $88.67 \pm 4 \mathrm{~kJ} / \mathrm{mol}$, a value lower than the one of the initial compound and thus providing a possible explanation for the increased activity at equal temperatures.

The second technique, real-time NMR spectroscopy, enabled us to observe the reaction progress on a molecular level at all times. For this purpose, the reaction occurred in sealed medium pressure sapphire tubes within the NMR instrument. Figure 7 shows the proton spectrum of ${ }^{13} \mathrm{C}$ labeled formic acid dehydrogenation by the in-situ generated catalyst. Formic acid appears as a doublet $(7.75$ and $8.30 \mathrm{ppm}, \mathrm{J}=218.8 \mathrm{~Hz})$ since the carbon-13 induced splitting occurs almost quantitatively, while the small peak in the center ( $8.03 \mathrm{ppm}$ ) results from unlabeled formic acid. Between spectrum 5 and 6 , all formic acid is dehydrogenated. Meanwhile, in the carbon-13 NMR, a carbon dioxide peak is emerging at (125.14 ppm).

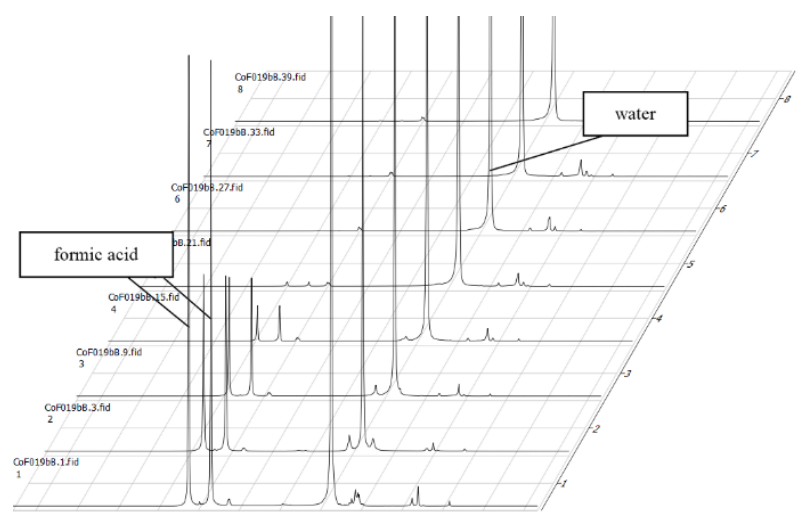

Figure 7 Formic acid dehydrogenation at $80^{\circ} \mathrm{C} ;{ }^{1} \mathrm{H} \mathrm{NMR}(400 \mathrm{MHz})$ spectrum with ${ }^{13} \mathrm{C}$ label FA; the conditions were identical as for the pressure measurements

${ }^{1} \mathrm{H}$-NMR measurements ensured that the catalyst is capable of completely consuming all formic acid, an important aspect when using pressure measurements to follow the reaction to completion.

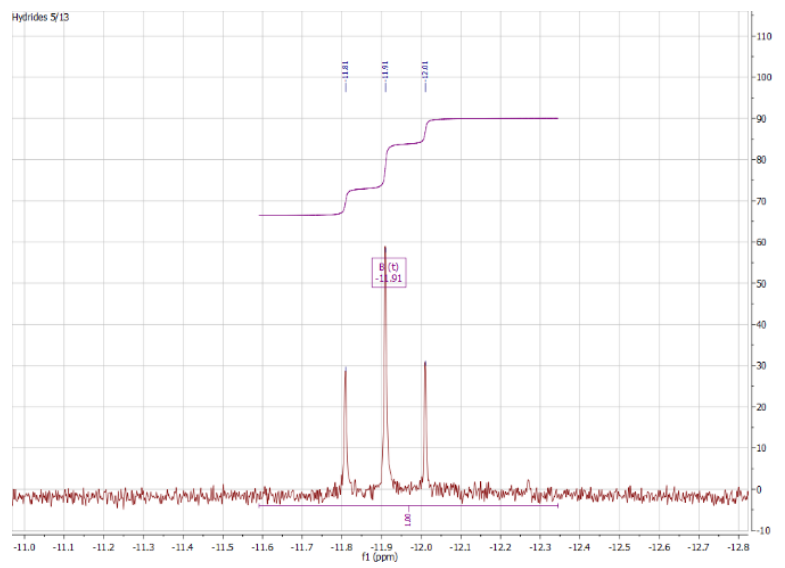

Figure 8 Signals in the hydride region were detected; triplet at $\delta$ 11.91 ( $t, \mathrm{~J}=40.2 \mathrm{~Hz}$ ) in $\mathrm{H}_{2} \mathrm{O}$ (benzene-d6 inlay)

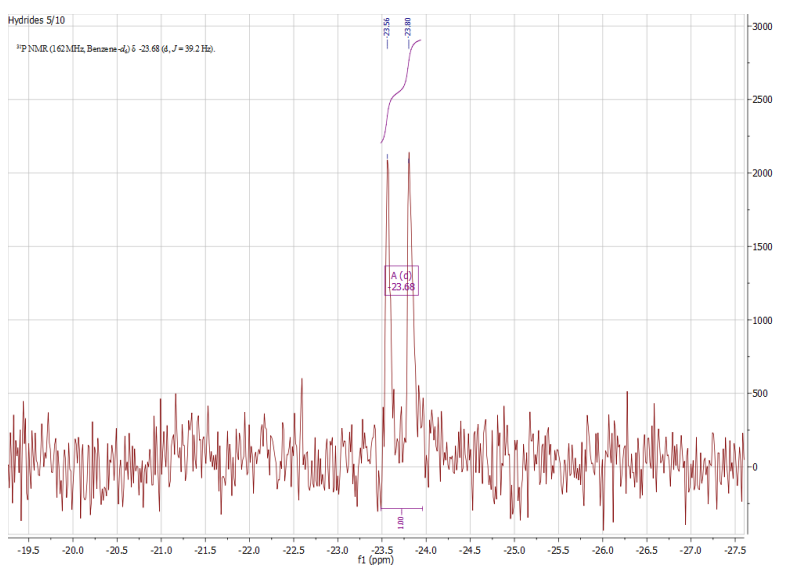

Figure $9{ }^{31} P$ NMR revealed a doublet at $\delta-23.68(d, J=39.2 \mathrm{~Hz})$ in $\mathrm{H}_{2} \mathrm{O}$ (benzene-d $d_{6}$ inlay)

Transition metal hydrides are crucial intermediates in many catalytic cycles, especially when transfer hydrogenation, 
hydrogen evolution or hydrogenation is observed. ${ }^{[30]}$ For this reason, we examined our compound towards metal hydrides and identified a triplet in the hydride region at $-11.91 \mathrm{ppm}(\mathrm{J}=40.2 \mathrm{~Hz}$, Figure 8). The next logical step was to look for a corresponding nucleus, which was coupling with the hydride. In ${ }^{31} \mathrm{P}$ spectra, a doublet at $\delta-23.68$ (Figure 9) featured an almost identical coupling constant $(J=39.2 \mathrm{~Hz})$. The two signals are not only linked by their almost identical coupling constant but also phosphorus decoupled measurement caused the triplet in the hydride region to collapse into a singlet signal, and in return, ${ }^{31} \mathrm{P}\{\mathrm{H}\}$ scans afforded a singlet in the ${ }^{31} \mathrm{P} N M R$ spectrum at the same place as the doublet appeared before. These findings serve as confirmation for a first coordination sphere where two phosphorus and one hydride are present.

\section{Conclusions}

We synthesized and evaluated a RAPTA-type compound towards its catalytic properties for selective formic acid dehydrogenation. The compound proved to be active, but the overall performance was below our expectations. The activity became significantly improved when introducing a second PTA in-situ, obtaining the mutually active structure $\left[\left(\eta^{6} \text {-benzyldimethylamine }\right) \mathrm{Ru}(\mathrm{PTA})_{2} \mathrm{H}\right]^{+}$, on which was reported earlier. The activation energies for both systems were determined, and NMR spectroscopy was employed to confirm the complete dehydrogenation of formic acid in the reaction mixture.

\section{Experimental Section}

Materials

Solvents and chemicals were purchased from commercial suppliers and used without further purification. $\mathrm{RuCl}_{3}\left(\mathrm{H}_{2} \mathrm{O}\right)_{n}(\mathrm{Rh}$ : $37-42 \%)$ was obtained from Precious Metals Online (PMO Pty Ltd). All solvents had at least HPLC grade (for synthesis) or analytical grade (p.a.).

\section{Instruments}

Microwave syntheses were carried out with a Biotage Initiator 2.0 microwave synthesizer ( $400 \mathrm{~W}$ ) in $20 \mathrm{~mL}$ microwave vials and equipped with magnetic stirring bars. NMR experiments were performed with a Bruker AV-400 $(5 \mathrm{~mm})$ for verification of the synthesized precatalysts while the kinetic measurements were recorded on a Bruker AVIII-400 in $10 \mathrm{~mm}$ medium pressure sapphire tubes. ${ }^{[31]}$ MestReNova 11.0.2 was used for spectra analysis and evaluation.

\section{Synthesis}

1-(cyclohexa-2,5-dien-1-yl)-N,N-dimethylmethanammonium chloride (1) A Birch reduction of $\mathrm{N}, \mathrm{N}$-dimethyl-1-phenylmethanamine $(11.7 \mathrm{~mL}$; density $=0.9 ; 10.5 \mathrm{~g}, 0.07765 \mathrm{~mol})$ with lithium afforded 1 -(cyclohexa-2,5-dien-1$\mathrm{yl})-\mathrm{N}, \mathrm{N}$-dimethylmethanammonium chloride as white crystalline compound $(63 \%$ yield $)$

$\left[\left(\eta^{6} \text {-benzyldimethylamine }\right) \mathrm{RuCl}_{2}\right]_{2}$ (2)

$300 \mathrm{mg} \mathrm{RuCl} \cdot 3 \mathrm{H}_{2} \mathrm{O}(1.147 \mathrm{mmol})$ were dissolved in a mixture of isobutanol, water and acetone $(6: 2: 2.2 \mathrm{~mL})$ in a $20 \mathrm{~mL}$ microwave flask, then (1) $(3.155 \mathrm{mmol}, 548 \mathrm{mg}$, excess 2.75$)$ was added. Flushing with nitrogen did not result in higher yields. The sample was then placed in a microwave oven and heated up to $145^{\circ} \mathrm{C}$ for 5 minutes. After cooling to $0^{\circ} \mathrm{C}$, the product was collected by filtration as dark red crystals, then washed with methanol, pentane and diethyl ether. Next, the crystals were dissolved in water/MeOH (80:20), filtered through celite to remove traces of unreacted metal. Finally, the filtrate was evaporated to obtain $323 \mathrm{mg}$ of an orange crystalline substance (yield $82 \%)$. ${ }^{1} \mathrm{H}-\mathrm{NMR}(400 \mathrm{MHz}$, DMSOd6) $\delta 10.77(\mathrm{~s}, 1 \mathrm{H}), 6.39-5.92(\mathrm{~m}, 5 \mathrm{H}), 4.07(\mathrm{~s}, 2 \mathrm{H}), 2.83(\mathrm{~s}, 6 \mathrm{H})$.
[( $\eta^{6}$-benzyldimethylamine $\left.) R u(P T A) C_{2}\right](3)$

The dinuclear compound (2) was dissolved in water (previously degassed by bubbling through $\mathrm{N}_{2}$ for 15 minutes) and warmed to $90^{\circ} \mathrm{C}$ under $\mathrm{N}_{2}$, then one equivalent of PTA was added. An immediate color change can be observed. After keeping the same temperature for ten more minutes, the water was evaporated and the compound collected, washed with 2propanol, ether and dried in vacuo. ${ }^{1} \mathrm{H}-\mathrm{NMR}(400 \mathrm{MHz}$, DMSO-d6) $\delta 10.78$ (s, 1H), $6.52-5.77(\mathrm{~m}, 5 \mathrm{H}), 4.05(\mathrm{~s}, 2 \mathrm{H}), 2.81(\mathrm{~s}, 6 \mathrm{H})$.

\section{Notes}

The authors declare no competing financial interest.

\section{Acknowledgments}

École Polytechnique Fédérale de Lausanne (EPFL), Swiss National Science Foundation (Grant 200020_162351), Swiss Competence Center for Energy Research (SCCER), Swiss Commission for Technology and Innovation (CTI) are thanked for financial support.

Keywords: formic acid, hydrogen, carbon dioxide utilization, formic acid dehydrogenation, hydrogen storage, homogeneous catalysis, RAPTA, PTA, ruthenium catalyst, sapphire tubes, multinuclear NMR spectroscopy, aqueous solution

[1] a) The Guardian, 2017, 10.03.2018; b) Wynes Seth, A Nicholas Kimberly, Environ. Res. Lett. 2017, 12, 074024. Thomas R. Anderson, Ed Hawkins, Philip D. Jones, Endeavour 2016, 40, 178-187.

[3] Andreas Züttel, Andreas Borgschulte, Louis Schlapbach, Hydrogen as a Future Energy Carrier, Wiley, 2011.

[4] Andrew F. Dalebrook, Weijia Gan, Martin Grasemann, Severine Moret, Gabor Laurenczy, Chem. Commun. (Cambridge, U. K.) 2013, 49, 8735-8751.

[5] Séverine Moret, Paul J. Dyson, Gábor Laurenczy, Nat. Commun. 2014, 5, http://dx.doi.org/10.1038/ncomms5017.

[6] Daniel Teichmann, Wolfgang Arlt, Peter Wasserscheid, Raymond Freymann, Energy Environ. Sci. 2011, 4, 2767 2773.

[7] Martin Grasemann, Gabor Laurenczy, Energy Environ. Sci. 2012, 5, 8171-8181.

[8] Albert Boddien, Christopher Federsel, Peter Sponholz, Dorthe Mellmann, Ralf Jackstell, Henrik Junge, Gabor Laurenczy, Matthias Beller, Energy Environ. Sci. 2012, 5, 8907-8911.

[9] a) Andreas Weilhard, Muhammad I. Qadir, Victor Sans, Jairton Dupont, ACS Catal. 2018, 8, 1628-1634; b) B. L. Bhargava, Yoshiro Yasaka, Michael L. Klein, J. Phys. Chem. B 2011, 115, 14136-14140.

[10] Cornel Fink, Sergey Katsyuba, Gabor Laurenczy, Phys. Chem. Chem. Phys. 2016, 18, 10764-10773.

[11] a) Céline Fellay, Ning Yan, Paul J. Dyson, Gábor Laurenczy, Chem. - Eur. J. 2009, 15, 3752-3760; b) Céline Fellay, Paul J Dyson, Gábor Laurenczy, Angew. Chem., Int. Ed. 2008, 47, 3966-3968.

[12] a) Jonathan F. Hull, Yuichiro Himeda, Wan-Hui Wang, Brian Hashiguchi, Roy Periana, David J. Szalda, James T. Muckerman, Etsuko Fujita, Nature Chem. 2012, 4, 383-388; b) Naoya Onishi, Shaoan Xu, Yuichi Manaka, Yuki Suna, WanHui Wang, James T. Muckerman, Etsuko Fujita, Yuichiro Himeda, Inorg. Chem. 2015, 54, 5114-5123; c) Cornel Fink, Gabor Laurenczy, Dalton Trans. 2017, 46, 1670-1676; d) Yuichi Manaka, Wan-Hui Wang, Yuki Suna, Hide Kambayashi, James T. Muckerman, Etsuko Fujita, Yuichiro Himeda, Catal. Sci. Technol. 2014, 4, 34-37. 
[13] Wan-Hui Wang, Shaoan Xu, Yuichi Manaka, Yuki Suna, Hide Kambayashi, James T. Muckerman, Etsuko Fujita, Yuichiro Himeda, ChemSusChem 2014, 7, 1976-1983.

[14] a) Sergio Sanz, Arturo Azua, Eduardo Peris, Dalton Trans. 2010, 39, 6339-6343; b) Chao Guan, Dan-Dan Zhang,

Yupeng Pan, Masayuki Iguchi, Manjaly J. Ajitha, Jinsong $\mathrm{Hu}$, Huaifeng Li, Changguang Yao, Mei-Hui Huang, Shixiong Min, Junrong Zheng, Yuichiro Himeda, Hajime Kawanami, Kuo-Wei Huang, Inorg. Chem. 2017, 56, 438-445.

[15] Irene Mellone, Nikolaus Gorgas, Federica Bertini, Maurizio Peruzzini, Karl Kirchner, Luca Gonsalvi, Organometallics 2016, 35, 3344-3349.

[16] Ryoichi Kanega, Naoya Onishi, Lin Wang, Kazuhisa Murata, James Muckerman, Etsuko Fujita, Yuichiro Himeda, Chem. Eur. J., DOI:10.1002/chem.201800428.

[17] a) Katerina Sordakis, Conghui Tang, Lydia K. Vogt, Henrik Junge, Paul J. Dyson, Matthias Beller, Gábor Laurenczy, Chem. Rev. (Washington, DC, U. S.) 2018, 118, 372-433; b) Andrea Álvarez, Atul Bansode, Atsushi Urakawa, Anastasiya V. Bavykina, Tim A. Wezendonk, Michiel Makkee, Jorge Gascon, Freek Kapteijn, Chem. Rev. (Washington, DC, U. S.) 2017, 117, 9804-9838; c) Cornel Fink, Mickael MontandonClerc, Gabor Laurenczy, Chimia 2015, 69, 746-752.

[18] Heng Zhong, Masayuki Iguchi, Maya Chatterjee, Yuichiro Himeda, Qiang Xu, Hajime Kawanami, Adv. Sustainable Syst. 2018, 2, 1700161-n/a.

[19] a) Yu Qian Tan, Paul J. Dyson, Wee Han Ang Organometallics 2011, 30, 5965-5971; b) Umar Ndagi, Ndumiso Mhlongo, Mahmoud E. Soliman, Drug Des., Dev. Ther. 2017, 11, 599-616.

[20] Robert H. Berndsen, Andrea Weiss, U. Kulsoom Abdul, Tse J. Wong, Patrick Meraldi, Arjan W. Griffioen, Paul J. Dyson, Patrycja Nowak-Sliwinska, Sci. Rep. 2017, 7, 43005.

a) Benjamin S. Murray, Maria V. Babak, Christian G. Hartinger, Paul J. Dyson, Coord. Chem. Rev. 2016, 306, 86114; b) Ronald F. S. Lee, Stéphane Escrig, Catherine Maclachlan, Graham Knott, Anders Meibom, Gianni Sava, Paul J. Dyson, Int. J. Mol. Sci. 2017, 18, 1869.

[22] Claudine Scolaro, Tilmann J. Geldbach, Sébastien Rochat, Antoine Dorcier, Christian Gossens, Alberta Bergamo, Moreno Cocchietto, Ivano Tavernelli, Gianni Sava, Ursula Rothlisberger, Paul J. Dyson, Organometallics 2005, 25, 756765.

[23] a) Donald A. Krogstad, Antonella Guerriero, Andrea lenco, Gabriele Manca, Maurizio Peruzzini, Gianna Reginato, Luca Gonsalvi, Organometallics 2011, 30, 6292-6302; b) Paul J. Dyson, David J. Ellis, William Henderson, Gábor Laurenczy, Adv. Synth. Catal. 2003, 345, 216-221.

[24] Antonella Guerriero, Maurizio Peruzzini, Luca Gonsalvi, Catalysts 2018, 8, 88.

[25] a) Masashi Yamakawa, Issaku Yamada, Ryoji Noyori, Angew. Chem., Int. Ed. 2001, 40, 2818-2821; b) Joseph S. M. Samec, Jan- E. Backvall, Pher G. Andersson, Peter Brandt, Chem. Soc. Rev. 2006, 35, 237-248.

[26] a) Manuel Iglesias, Luis Oro, Eur. J. Inorg. Chem. 2018, 10.1002/ejic.201800159; b) Iguchi Masayuki, Zhong Heng, Himeda Yuichiro, Kawanami Hajime, Chem. - Eur. J. 2017, 23, 17788-17793.

[27] Mickael Montandon-Clerc, Andrew F. Dalebrook, Gábor Laurenczy, J. Catal. 2016, 343, 62-67.

[28] Henrietta Horváth, Gábor Laurenczy, Ágnes Kathó, J. Organomet. Chem. 2004, 689, 1036-1045.

[29] Sandra Bolaño, Gianluca Ciancaleoni, Jorge Bravo, Luca Gonsalvi, Alceo Macchioni, Maurizio Peruzzini, Organometallics 2008, 27, 1649-1652.

[30] Rebecca E. Adams, Tod A. Grusenmeyer, Audrey L. Griffith, Russell H. Schmehl, Coord. Chem. Rev. 2018, 362, 44-53.

[31] Severine Moret, Paul J. Dyson, Gabor Laurenczy, Dalton Trans. 2013, 42, 4353-4356. 
WILEY-VCH Title

\section{FULL PAPER}

Text for Table of Contents

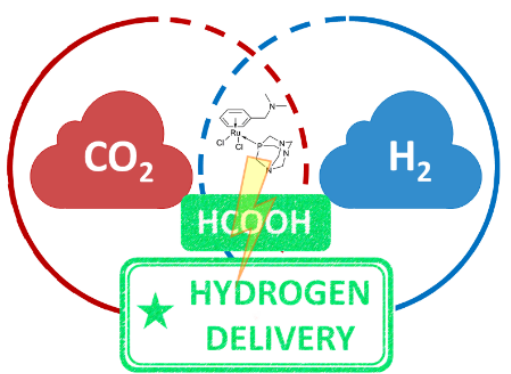

Author(s), Corresponding Author(s)*

Page No. - Page No.

Title

Author(s), Corresponding Author(s)*

Cornel Fink*, Lu Chen, and Gábor Laurenczy*

Page No. - Page No.

Additional Author information for the electronic version of the article.

Gábor Laurenczy: ORCID: 0000-0002-4354-4521

Author: ORCID identifier

Author: ORCID identifier 
Cornel FINK

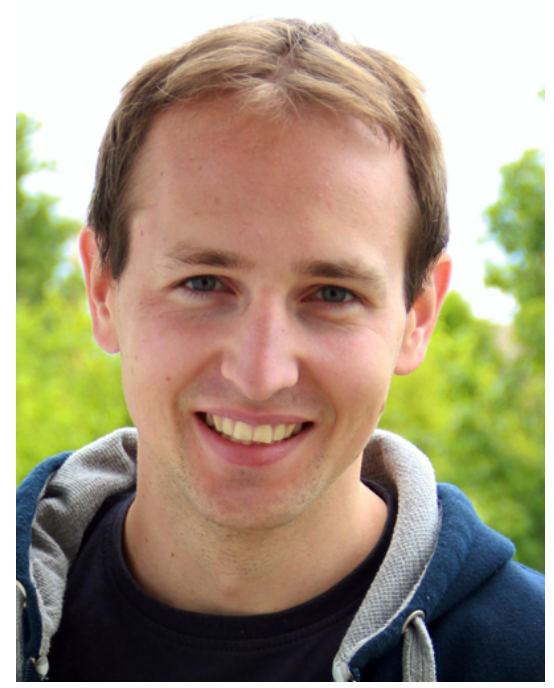

Cornel Fink finished his undergraduate studies in the University of Vienna, including an Erasmus stay in Sweden, Gothenburg University. After an Erasmus Practicum at the EPFL in the Group of Prof. Kay Severin, he started his Ph.D. at the EPFL in the GCEE group under the supervision of Prof. Gábor Laurenczy.

\section{Lu CHEN}

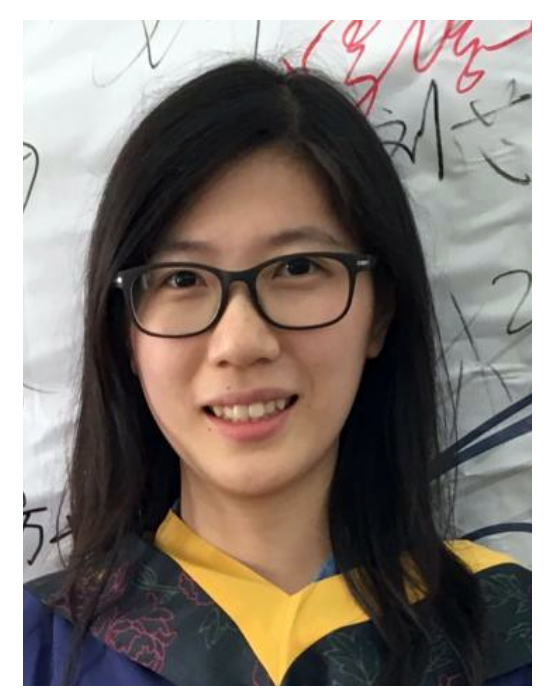

Lu Chen finished her undergraduate studies in Chemical Engineering at the Tianjin University (China). After three years of study, she received a double master degree from both, the Chinese Academy of Sciences and the Technical University of Denmark. In 2016, she started her Ph.D. at the EPFL in the GCEE group under the supervision of Prof. Gábor Laurenczy. 
Gábor LAURENCZY

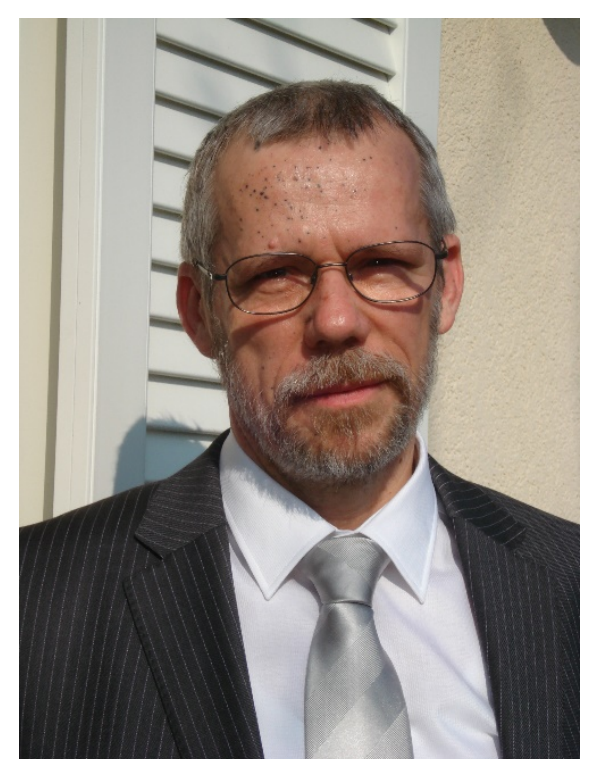

Gábor Laurenczy finished his studies (MSc, chemistry) at the University of Debrecen Hungary in 1978, three years later he obtained a PhD (inorganic chemistry). In 1985 he became assistant professor (Dept. of Inorganic Chemistry) and in 1991 he made his habilitation (Hungarian Academy of Sciences). In 1985 he moved to Switzerland where in 1991 he became assistant professor at the University of Lausanne and from 2001-2009 he was master of teaching and research at EPFL. Since 2010 he has been a professor at École Polytechnique Fédérale de Lausanne and head of the Group of Catalysis for Energy and Environment. 